\title{
El IMAGinaRIo DE LA COMIDA EN LA POESÍA DE PABLO DE ROKHA *
}

\author{
Juan Gabriel Araya Grandón** \\ Arnaldo Enrique Donoso Aceituno***
}

\section{Resumen}

La poesía de Pablo de Rokha está atravesada por un complejo sistema de representación de alimentos, recetas, espacios de preparación y consumo, cuerpos animales, vegetales y humanos, afectos positivos y negativos. Denominamos imaginario de incorporación de la comida a este sistema de representación. Analizamos las implicancias textuales y discursivas de este imaginario, a fin de relevar la poetización de las comidas y bebidas como un acontecer material, intensivo, corporal y utópico.

Palabras clave: Pablo de Rokha, imaginario de incorporación, comidas, utopía.

\section{THE PRINCIPLE OF INCORPORATION IN THE POETRY OF PABLo de RoKHA}

\begin{abstract}
The poetry of Pablo de Rokha is crossed by a complex system of food's representation, recipes, places for preparation and consumption, animal, plants and human bodies, and positive and negative affections. We call imaginary of food incorporation to this system of representation. The aim of this paper is to analyse the textual and discursive implications of this imaginary in order to enhance meals and beverages poetization as a material event, intensive, corporal and utopic.
\end{abstract}

Keywords: Pablo de Rokha, principle of incorporation, meals, utopia.

Recibido: 25-06-2014

Aceptado: 09-01-2015

* Este trabajo forma parte del proyecto de investigación regular DIUBB 1434254/R, “El acontecimiento de la comida en la poesía chilena", Dirección de Investigación, Universidad del Bío-Bío. Los autores son, en orden respectivo, investigador responsable y co-investigador.

** Postgrado en Literatura Hispanoamericana, Instituto Caro y Cuervo, Bogotá. Profesor Titular, Departamento de Artes y Letras, Universidad del Bío-Bío, Concepción, Chile. jaraya@ubiobio.cl

*** Magíster (c) en Literaturas Hispánicas, Universidad de Concepción. Investigador Universidad del Bío-Bío, Concepción, Chile. arnaldodonoso@udec.cl 
Porque, para componer este señorial libro, no perdí ni empleé ni más ni menos tiempo que el preciso para reponer mis fuerzas corporales, vale decir, para comer y beber. Esa es la hora más propicia para escribir sobre estos elevados temas y profundas ciencias, como muy bien solía en hacerlo Homero, punto de referencia de todos los filólogos y Ennio, padre de los poetas latinos, según testimonio de Horacio, de quien un malandrín dijo que sus cantos más olían a vino que a aceite.

François Rabelais

La crítica (Sepúlveda Llanos, Lavín Cerda, Concha, Nómez, Ferrada, Rodríguez Monarca, Sepúlveda Eriz) ha destacado no solo el valor poético de Epopeya de las comidas y bebidas de Chile $(1949,1957,1965)$ de Pablo de Rokha (1894-1968), sino además la revolucionaria concepción de lo nacional-popular que transmite esta prodigiosa relación poéticogastronómica. De acuerdo a esta línea de análisis, se proyecta la expresión gastronómica del pueblo de Chile al campo histórico-social como respuesta a la desterritorialización, blanqueamiento, limitación y reducción sistemática de las prácticas culturales por parte de los dispositivos de hegemonía cultural; por ejemplo, el reduccionismo de lo pintoresco o el del folclore (Gramsci). En buena medida, la base de estas reflexiones se encuentra en el polarizado contexto de producción de lo que hoy conocemos como Epopeya de las comidas y bebidas de Chile (en adelante Epopeya...). El poema vio la luz en 1949 bajo el nombre de Teogonía y cosmología del libro de cocina (Teogonía... en lo sucesivo), al interior de un conjunto de escritos de diversa índole titulado Arenga sobre el arte, ${ }^{1}$ en la sección "Carta magna del continente". Arenga sobre el arte fue escrito durante una prolongada gira cultural que Pablo de Rokha efectuó por América gracias al estipendio que le concedió el gobierno de Juan Antonio Ríos, mandatario de la República de Chile entre 1942 y 1946, y sucesor de Pedro Aguirre Cerda. Desde 1944 hasta 1949 de Rokha viajó, dictó conferencias y tomó contacto con diversos artistas e intelectuales latinoamericanos.

1 Es preciso recordar Arenga sobre el arte incluye también el poemario El valle pierde su atmósfera de Winétt de Rokha. 
El extenso recorrido por tierras hermanas profundizó en de Rokha un sentimiento americanista. La contingencia lo impulsó a escribir, con portentoso realismo, retratos de la vida de campesinos y proletarios como reflejo de sus anhelos sociales. En 1946, fallece el presidente Ríos. Se celebran votaciones y triunfa Gabriel González Videla, gracias al pacto constituyente entre su colectividad, el Partido Democrático, el Partido Comunista (PCCh) y el Partido Liberal. Dos años después, en septiembre de 1948, instigada por la elite y EE.UU., la gubernatura de González Videla vira políticamente y decreta la proscripción del PCCh a través de la "Ley Permanente de Defensa de la Democracia", más conocida como "la ley maldita". Militantes y simpatizantes del PCCh son eliminados de los registros electorales, perseguidos y relegados. Pablo de Rokha decide radicarse en Argentina hasta entrado 1949. Ese año el poeta regresa a Chile y publica Arenga sobre el arte por el sello Multitud.

Fernando Lamberg menciona que de Rokha leyó fragmentos de Teogonía... a un grupo de amigos en el año 1943 en la comuna de La Cisterna (126). El texto fue publicado con el título definitivo de Epopeya... hacia 1957, en Autorretrato de Chile, colección de textos dirigida por Nicomedes Guzmán e impresa por la editorial Zig-Zag. Anales de la Universidad de Chile también lo publicó con ese título en su número 118 (abril-junio de 1960), en un especial dedicado a las fiestas nacionales. En 1965, el poema reapareció en un volumen doble por Editorial Universitaria que reunía Epopeya... y el Canto del macho anciano.

Con todo, ambos nombres, Teogonía... y Epopeya... connotan una dimensión fabulosa, de género mayor. El segundo nombre viene a subrayar el carácter nacional del tratado. En efecto, como señalábamos al inicio, el inscribir poéticamente lo nacional-popular a través de las apetencias gastronómicas de un pueblo no se había hecho con la fuerza torrencial que de Rokha imprime en Epopeya... El amplio consenso en esta materia nos mueve a evitar la repetición e indagar de un modo más específico en la relación entre comida y poesía en la obra rokhiana. Avancemos que Epopeya de las comidas y bebidas de Chile no es un caso excepcional, es parte de una red bien urdida, de una cuerda persistentemente pulsada. El corpus rokhiano se encuentra cruzado por un sistema de representación de alimentos, recetas, espacios de preparación y consumo, cuerpos animales, vegetales y humanos, afectos positivos y negativos de varias capas. En un sentido específico, 
las referencias alimentarias rokhianas son un acontecer intensivo de sabores, texturas, formas, temperaturas, colores, mixturas y aromas, una cartografía poética-nutricional-gastronómica que incluye concreciones históricas, sociales, culturales y geográficas. En adelante, nos referiremos a este sistema de representación como imaginario de incorporación de la comida (Fischler, Montecino).

El concepto de incorporación refiere al gesto vital de hacer "traspasar al alimento la frontera entre el mundo y nuestro cuerpo, lo de afuera y lo de dentro" (Fischler 65-66). Este gesto, en apariencia simple, implica complejas interacciones a nivel biológico, ecológico y cultural. En un nivel, los alimentos forman parte de nuestro sentido de identidad, pertenencia o diferencia respecto de un grupo o cultura. Claude Lévi-Strauss, padre de la antropología estructural, entendía las prácticas alimentarias como un sistema de inclusiones y exclusiones determinadas por la cultura: el hombre come al interior de una cultura y esta ordena lo comible y lo incomible. Asimismo, los alimentos y las prácticas alimentarias otorgan, según Claude Fischler, un sentido de contigüidad y continuidad a los territorios del yo y del mundo, del individuo y la sociedad, del hombre y la naturaleza, del microcosmos y del macrocosmos (68). Somos omnívoros, nos alimentamos de vegetales y animales diversos para mantener el equilibrio bioquímico del organismo humano, pero, comer es, además, parte del relato evolutivo, pues los cambios de nuestras prácticas alimentarias han materializado modificaciones fisiológicas y genéticas (Allen 40, 73). En paralelo al desarrollo de nuestra capacidad de adaptación ambiental y de nuestra predisposición biológica para digerir una enorme variedad de alimentos, se configuró un universo simbólico de incontables gustos, dietas y preparaciones culinarias (Allen 41).

Desde un enfoque ecocrítico, el concepto de incorporación se relaciona directamente con el de transcorporalidad, esto es el intercambio material a través de cuerpos animales, vegetales, humanos y el mundo concreto. En otras palabras, es la capacidad de la materia para conectar y modificar cuerpos, lugares y ecologías (Alaimo, Material 69; Bodily 476). Como se colige, los alimentos se inscriben como materias transcorporales. El concepto de transcorporalidad encierra una inquietante paradoja: el afuera nunca se encuentra fuera de nosotros. Al decir de Harold Fromm, el afuera "corre a través de nosotros en olas sin fin". Si lográsemos mirarnos en un video time lapse microscópico, plantea Fromm, "podríamos ver el 
agua, el aire, la comida, los microbios y toxinas irrumpiendo en nuestros cuerpos, así como también cuando nuestros cuerpos secretan, excretan y exhalan los materiales procesados" (95). Los alimentos son cuerpos que se mueven entre lo biológico y lo cultural, entre lo individual y lo social. Se encuentran en un plano en el que la función nutritiva conecta lo material y lo simbólico (cf. Fischler 14-15) como máquinas que se acoplan.

El imaginario de incorporación rokhiano comienza a configurarse tempranamente. Establezcamos de entrada que no espera ni se centra en Epopeya... Si repasamos Los gemidos (1922) ${ }^{2}$ tenemos que en "Epitalamio" se describe con irreprimible parafernalia tipográfica una hirviente "cazuela aromática, el guiso de frejoles rojos y el filete al vapor, la malaya nueva con espárragos, con espárragos y el puré goloso, y un pato imberbe, JOVENCITO, perfuma el asador de maqui nacional; [mientras] entona el agua útil, errantes cantos errantes y la luz juega con los pájaros" (117). Y más adelante se señala en "Égloga": "todas las viñas peinan cabellos amarillos, peinan cabellos amarillos; los techos y zarandas están llenos de zapallos y, á las 9 de la mañana, todos los vecinos acomodados de las aldeas y las granjas están, están tomando mate con tortilla, café con queso asado y aguardiente [...] orillando el brasero, melancólicos, cándidos, románticos" (310-311).

La seña es persistente. Casi cuarenta años después, en Acero de invierno (1961), de Rokha elabora una "Rotología del poroto":

Son famosos e ilustres comidos fiambres en ciudades lluviosas, cuando los tejados de Junio y Julio lagrimean la madrugada, y está crujiendo el navío del invierno como el pantalón de un Dios apuñalado

trágicamente después de haber saboreado aquella gran chupilca democrática del parroquiano, no digamos licoreado, sino como filo de botella, es decir, el pigüelo del abuelo licantenino de los comienzos del "novecientos" el cual se parece a una tortilla de rescoldo

2 Uno de los textos vanguardistas más importantes del siglo pasado, "más allá de todos los ísmos", como dijera Salvador Reyes. Publicados el mismo 1922, tenemos el Ulysses de James Joyce, Trilce de César Vallejo, The Waste Land de T. S. Eliot, Desolación de Gabriela Mistral, Paulicéia Desvairada de Mário de Andrade o los Veinte poemas para ser leídos en el tranvía de Oliverio Girondo. Pensamos, al igual que Reyes, que Los Gemidos es parte de estas obras fundamentales. 
y de aliñar el causeo con limón tronador, cilantro, un ají rajado, brotes de enorme relación dionisíaca, cuajados en la cebolla estalladora del gran crepúsculo vecinal,

remojándolo con esos pipeños enfurecidos por ejemplo de los viñedos de Ranguelmo. (Epopeya del 241[4])

Reflota el motivo en "Campeonato de rayuela", de Estilo de masas (1965):

Cuando "la gran quemada" se produce,

un horizonte de chicharrones con harina o caldo de gallo castellano o costillar de chancho con

ajo,

despunta desde el oriente cordillerano, y el invierno

arroja la manta de castilla enormemente mojada por la gran ventana del "18 de septiembre" [...]

“¡Puchas que tira el tejo bien pasao mi compaire Ño Toribio!”, reclama el guatón Corvalán, pellejo de carnero, atragantándose de picante de guatitas: “ ¿Y cómo

anda la chanfaina y el causeo de culitos de vacuna, para la guata?" (Epopeya del 281)

Por su parte, en "Tonada a la posada de don Lucho Contardo" destaca

El chicharrón y la chanfaina, tan amada del hombre lacustre que cría corderos en las laderas de la laguna natal, el chicharrón de chancho enamorado, de chancho como chancho de gordazo, enharinado y floreal, cocido con vino en el guargüero, lo saboreábamos mi abuelo y yo a la orilla de los braseros enfurecidos de don Lucho Contardo [...]. (Epopeya del 283)

Los ejemplos son inagotables. Si bien, de acuerdo a la ponderación de Jaime Concha (1998), la "dimensión rural es notoria y se impone como un proceso de exploración subjetiva en los trasmundos provincianos, aldeanos, campesinos, elementales del interior del país" (21), la poesía rokhiana, ejemplifica la noción de polifonía bajtiniana, en su sentido de orquestación retórica a partir de una determinada experiencia narrativa. Aunque mediada por una conciencia subjetiva, la poesía rokhiana no se 
sedimenta ni en el sujeto ni en los efectos estéticos. La heterogeneidad y fluidez del "soplo de energía material" que la atraviesa obliga a ampliar la noción de polifonía más allá de los sujetos humanos. Los alimentos y los lugares son agentes en el imaginario de incorporación. Representan más que un efecto o figuración composicional o teórica, pues atraviesan los territorios del yo y del socius, encarnando una potencia que enfrenta la idea secular que define la práctica literaria: su carácter eminentemente urbano.

Como ha señalado Fernando Aínsa, la actitud del intelectual americano frente a las grandes ciudades ha sido siempre contradictoria. La literatura y el pensamiento hispanoamericanos prodigan numerosos ejemplos de desconfianza al mito civilizador de los espacios urbanos, frente a otros tantos ejemplos de fe ciega, utópica, en los proyectos modernizadores (23, 24-28). A este respecto, un índice sugestivo que visibiliza esta tensión en la poesía de Pablo de Rokha es el carácter abyecto de la circulación de la carne por la ciudad que apreciamos en el poema "Matadero": "Las murallas, los ladrillos, el aire seboso, cuajado del establecimiento hiede á cosas idiotas, á brutalidad, á naturaleza manchada, á comercios, á cocinería, á billetes, y las ovejas melancólicas de Garcilaso se venden por kilos, se venden por kilos, —guatas, patas—, se venden por kilos... ..." (Los gemidos 277). ${ }^{3}$ Este lugar de intercambio de carne y billetes tiene su opuesto en la poesía de Pablo de Rokha en las celebraciones de cosechas, rodeos, onomásticos, bautizos, velorios, santos, casorios, tomateras, esquinazos, malones, rayuelas, funerales, vendimias y trillas, indicando el lugar propicio de cada condumio: "Hualañé invita al ponche y al mosto, a aquellos pigüelos soberbios de don Juan de Dios Alvarado, en esa enorme chicha bautismal de doña Rosa Díaz, la tía del Mataquito" (21). O bien,

Y la empanadita fritita, picantoncita y la sopaipilla, que en tocino ardiente gimieron, se bendice entre trago y trago, a1 pie de los pellines del Bío-Bío, en los que se enrolla el trueno con anchos látigos,

3 Una sensibilidad similar puede observarse en el poema de Jorge Luis Borges "Carnicería", de Fervor de Buenos Aires (1923). 
pero nunca la iguala a la paloma torcaz, sabroseada en los rastrojos de julio, en la humedad incondicional de tal época, entre fogatas y tortillas, tomando en la bota de cazador esos enormes vinos que huelen a pólvora y a amistad o a1 zorzal tamaño del viñedo, que es el puñal agrario del lamento. (9)

Puede observarse cómo en Satanás (1927) el hablante rokhiano recuerda

los chicharrones y de los pigüelos y de los causeos de don Vicho y del poruña Abdón Madrid y de la tonta Martina y del compadre Anacleto

y del borracho Juan de Dios Pizarro y Juan de Dios Chaparro

[...] las piaras costinas, tan olorosas a cochayuyos y a sentimiento de Iloca. (Epopeya del 102[5])

En Escritura de Raimundo Contreras (1929), en "El descubrimiento de la alegría", refiere:

entran las guitarras y un gran chacolí rancagüino llora la cueca llorada del roto choro la llora pero la llora realegremente remolienda de la empanada y la aceituna y el carajo de Raimundo Contreras gritando y cantando como un arrollado picante repuchas la naranjada de invierno que anda mamando el guaina

¿en dónde llevará entonces esa tal canasta oceánica de tortillas de rescoldo y aquella cachada de aguardiente y aquel ancho poncho huacho que declama en la proa de las noches? (Epopeya del 119)

Se desprende que en el imaginario de incorporación rokhiano la valoración del espacio citadino es diferente a la de los escenarios rurales. Si el primero es el del intercambio, es decir, un espacio cuadriculado y operativo, un no-lugar, ${ }^{4}$ los segundos son abiertos y permeables, ligados a la fiesta. En su paso de provincia en provincia el hablante otorga

4 Originalmente acuñada por Marc Augé (1992) y actualmente avivada por los estudios ecocríticos ibéricos, la noción de no-lugar refiere a aquellos espacios cuyo espesor antropológico es igual a cero. Un no-lugar "es un espacio que no puede definirse ni como espacio de identidad ni como relacional ni como histórico" (83). Piénsese en espacios que son idénticos en todo el mundo, como carreteras, locales de comida rápida, malls, cajeros automáticos, aeropuertos, carreteras, peajes, etcétera. 
densidad social al discurso. Son escenarios heterotópicos (Foucault), es decir "utopías situadas", "lugares reales fuera de todos los lugares" (21) o "lugares que se oponen a todos los otros, que están destinados de algún modo a borrarlos, a neutralizarlos o a purificarlos" (29-30).

En conexión con lo anterior, uno de los aspectos notables del discurso rokhiano es aquel que se desprende de la relación entre sentido del lugar y producción alimenticia. Antes de los sabores estandarizados, Pablo de Rokha vindica la producción y consumo alimentario local y artesanal. Hoy, aunque inmersos en un contexto global de "suplantación gastronómica" o "colonialidad de sabores y paladares" (Albán 15, 22), caracterizado, por ejemplo, por la mundialización de comidas rápidas, los utensilios desechables, los no-lugares (McDonald's, Starbucks, KFC, etc.; cf. Sepúlveda Eriz 205-206), y el multiculturalismo posmoderno de la comida fusión, los alimentos y preparaciones locales siguen siendo consideradas un arte y una marca de identidad territorial que se asocia a la salud, o agencia una salud (Fernández-Armesto 334-335).

Sin menguar su peso específico, la revolucionaria poesía de Pablo de Rokha establece relaciones transtextuales con prodigiosas heterotopías carnívoras de la literatura universal: los holocaustos y oblaciones bíblicas, el ditirambo dionisíaco de exultación de la abundancia de los frutos, el mito heleno de la cornucopia o cuerno de la abundancia, el exotismo de ciertos relatos orientales, las bodas de Camacho el rico y los convites pantagruélicos. ${ }^{5}$ Sirva como ejemplo de las resonancias bíblicas en las ficciones culinarias rokhianas, las siguientes líneas del poema Moisés, de 1937: “Decía el pueblo: «el aroma de los ajos y los pescados y los gansos y las toronjas / y las cebollas, / el olor a fritanga y a carne asada, nos perfuma la memoria del corazón, / afligiéndonos, haciendo con nuestros recuerdos una gran cosecha de llantos, y queremos carne, carne, como en el Egipto»" (Epopeya del 163).

Esta insistencia carnívora se relaciona en de Rokha a diversas huellas rabelesianas y cervantinas. En el poema "Demonio a caballo", el hablante aconseja "emborracharse de vino y de mito a Rabelais, dialogar en piedra

5 De Rokha en su juventud leyó a Rabelais, Voltaire y Nietszche, entre otros autores "prohibidos". En parte, estas lecturas le costaron la expulsión del Seminario Conciliar de San Pelayo. Precisamente en el seminario, el joven Carlos Díaz Loyola fue bautizado por sus compañeros como "el amigo piedra", apodo que por extensión semántica derivó en "roca" y más tarde al seudónimo Pablo de Rokha. 
muerta al Alighieri y al Tintoretto, sentados en cuatro bancos de humo y eternidad, precisamente, tranquear el jamelgo de arriendo de don Miguel de Cervantes Saavedra" (de Rokha, Mis grandes poemas 132). En "Canto del macho anciano" el sujeto rokhiano recuerda "al amigo Rabelais y al compadre Miguel de Cervantes tomando mi cacho labrado en los mesones de las tabernas antiquísimas, las bodegas y las chinganas sol de invierno" (229); y en "Oceanía de Valparaíso" el poeta se encuentra "con espanto acumulado en Rabelais y la gran angustia de las civilizaciones perdidas" (262). Profundizando en esta relación, al realizar una lectura contrastiva entre segmentos de Gargantúa y Pantagruel, ${ }^{6}$ el pasaje de las bodas de Camacho el rico de El Quijote y la Epopeya... llama la atención el inventario de animales (aves, caprinos, vacunos, presas de caza, etc.) destinados a la fiesta:

Lo primero que se le ofreció a la vista de Sancho fue, espetado en un asador de un olmo entero, un entero novillo; y en el fuego donde se había de asar ardía un mediano monte de leña, y seis ollas que alrededor de la hoguera estaban no se habían hecho en la común turquesa de las demás ollas; porque eran seis medias tinajas, que cada una cabía un rastro de carne: así embebían y encerraban en sí carneros enteros, sin echarse de ver, como si fueran palominos; las liebres ya sin pellejo y las gallinas sin pluma que estaban colgadas por los árboles para sepultarlas en las ollas no tenían número; los pájaros y caza de diversos géneros eran infinitos, colgados de los árboles para que el aire los enfriase. Contó Sancho más de sesenta zaques de más de a dos arrobas cada uno, y todos llenos, según después pareció, de generosos vinos; así había rimeros de pan blanquísimo como los suele haber de montones de trigo en las eras; los quesos, puestos como ladrillos enrejalados, formaban una muralla, y dos calderas de aceite mayores que las de un tinte servían de freír cosas de masa, que con dos valientes palas las sacaban fritas y las zabullían en otra caldera de preparada miel que allí junto estaba [...] En el dilatado vientre del novillo estaban doce tiernos y pequeños lechones, que, cosidos por encima, servían de darle sabor y enternecerle. Las especias de

6 Relatos publicados fragmentariamente "en forma de libritos populares" — dice Anatole Franceentre los años 1532 y 1564, y que luego fueron reunidos en una sola edición. 
diversas suertes no parecía haberlas comprado por libras, sino por arrobas, y todas estaban de manifiesto en una grande arca. (Cervantes, web)

Dicho esto, prepararon la comida, para la que, como extraordinario, fueron asados 16 bueyes, 3 terneras, 32 terneros, 63 cabritos domésticos, 398 cochinillos de leche, 220 perdices, 700 becadas, 400 capones de Londonois y Cornwaille, 6.000 pollos y otras tantas palomas, 600 gallinetas, 1.400 liebres y 303 avutardas y 1.700 capones. Caza no pudo cobrarse mucha tan repentinamente, por lo que sólo tuvieron 11 jabalíes, que les envió el abad Turpenay, 18 animales salvajes que les regaló el señor Grandmón, 140 faisanes del señor Essars y algunas docenas de palomas zoritas, cercetas, alondras, chorlitos, zorzales, ánades, avefrías, ocas, garzas, cigüeñas, aguiluchos, patos, pollos de la India y otros pájaros, abundantes guisados y la mar de verduras. Todo ello fue muy bien dispuesto [...] sirvieron de beber en abundancia. (Rabelais 179)

Hermoso como vacuno joven es el canto de las ranas guisadas entre perdices [...] el camarón del Huasco es rico, chorreando vino y sentimiento [...] ¿qué me dicen ustedes de un costillar de chancho con ajo, picantísimo, asado en asador de maqui, en junio, a la rivera del peumo o la patagua o el boldo [...] o bien la guañaca en caldo de ganso, completamente talquino o licantenino de parentela?, no, la codorniz asada a la parrilla se come, lo mismo que se oye "el Martirio" en las laderas aconcagüinas y la lisa frita en el Maule, en que el pejerrey salta a la paila sagrada de gozo [...] Los pavos grandazos que huelen a verano y son otoños de nogal, casi humano, los como en todo el país. (Epopeya de las 7)

De acuerdo a Fidel Sepúlveda (1970), a nivel retórico las referencias culinarias se suceden "sin remanso para el respiro, en que las evocaciones temáticas y los elementos que las constituyen se encadenan en asociaciones urgidas por el azar y, sin embargo, no hay desorden, no hay capricho, no hay gratuidad: hay un ritmo que organiza y metaboliza lo heteróclito" (170). Leemos en ello que el imaginario rokhiano de incorporación se configura de forma palimpséstica sobre la base del conocimiento de la tradición literaria universal y la tradición gastronómica chilena. Desde esta perspectiva, la orgía gastronómica se 
insinúa como una expresión popular, mestiza, barroca, letrada, pero con un sustrato oral. ${ }^{7}$ En de Rokha, este patrón literario se relaciona con un epos heroico. Los alimentos poetizados van ganando cuerpo a medida que pasan "a la historia agigantados en su presencia de mitos". Sujetos textuales y alimentos hacen gala de su pertenencia a una comunidad mítica donde todo es memorable o heroico: "Un vino caliente torna más heroica la madrugada de las remoliendas", "la castaña da gran intimidad heroica a la chimenea", "es menester cuidarse del oleaje afirmándose en la color vertical de Chile que los rotos heroicos tragan con moco y todo" (Epopeya del 210-211). Es esta la dimensión mítica que ha observado la crítica: las comidas desbordan embriaguez dionisiaca. No obstante este epos es tan heroico como trágico (cf. Ferrada, web). Conecta con flujos de muerte que son resistidos a través de la fiesta y el licor:

báñese en chacolí fuertón y corajudo

y váyase a echar esa última cana al aire mucho antes de que la pelada

le coloque la espalda contra la eternidad y el pecho frente al cielo $[\ldots$

Cuando comienza la llovizna hay vacas difuntas llorando en los acantilados y braman las quebradas. (de Rokha, Epopeya de las 14)

La potencia que brota de la apreciación heroica de los alimentos es característica del tono dionisíaco. "Bajo la magia de lo dionisiaco no sólo se renueva la alianza entre los seres humanos: también la naturaleza enajenada, hostil o subyugada celebra su fiesta de reconciliación con su hijo perdido, el hombre. De esta manera espontánea ofrece la tierra sus dones" (Nietzsche 44). Para Bataille, lo divino de Dionisos es "la inocencia del instante", la figuración de un dios "ciego a las consecuencias, es la ausencia de razón y el grito sin esperanza -que sólo tiene la instantaneidad del rayo- de [...una] tragedia [...] donde no hay individualización del héroe" (28-29). Así, lo que aspira a exteriorizarse es un devenir colectivo de materias heterogéneas más que una expresión de pura subjetividad:

7 De acuerdo al poeta, el "barroco no es una sobrecarga de material, es un lenguaje gigantesco. Y a Latinoamérica le corresponde ese lenguaje por sus desfiladeros, sus grandes ríos, sus sierras escarpadas, sus majestuosas cordilleras, sus desiertos, sus selvas [...] el barroco popular organizado, es el lenguaje del mestizaje indohispánico" (cit. Ferrero 113). 
comienza el poema de la saturación espiritual del humo y así como la olorosa aceituna de Aconcagua, con la cual sólo es posible saborear los patos borrachos con apio y bien cebados y regados con cien botellas, la olorosa aceituna de Aconcagua se macera en salmuera de las salinas de Iloca, únicamente, la carne sabrosa de los bucaneros y la piratería se ahuma con humo, pero con humo de ulmo en la frontera. (9)

En el ditirambo dionísiaco el hombre es estimulado hasta la intensificación máxima de todas sus capacidades simbólicas. El goce gastronómico rokhiano se centra en el respeto, el elogio y la admiración de plantas cosechadas o animales criados por los hombres que los consumen. Para algunos críticos, este goce se manifiesta discursivamente como un restablecimiento utópico del equilibrio hombre / naturaleza. Naín Nómez ha conceptuado la poesía rokhiana como una búsqueda por "retener lo duradero del presente y reordenar el futuro desde una perspectiva visionaria y utópica" (web). Como se sabe, el discurso literario utópico comprende tanto a la descripción de una sociedad imaginaria emplazada en un lugar sin lugar, emplazado a su vez en un tiempo sin tiempo, a la que subyace de una crítica a la realidad real, como a los textos y discursos contemporáneos de intención utópica, que elaboran una "proyección dialéctica de la historia del hombre hacia un futuro concebido cada vez como el rechazo del presente" (Alonso et al. 30). Northrop Frye ha señalado en "Varieties of Literary Utopias" (1965) que el procedimiento de construcción utópico tiene dos principios prácticamente invariables: 1) el comportamiento de la sociedad utópica es descrito ritualmente, en sus actos sociales significativos (324), y 2) el ritual parece incomprensible, deviniendo racional cuando su significancia es explicada: el ícono de lo racional y del diseño consciente es la ciudad (325).

El imaginario rokhiano de incorporación de la comida transgrede la utopía en su concepción canónica. Como expresión utópica, los banquetes rokhianos serían indudablemente la descripción literaria individuada de una sociedad imaginaria a través de sus rituales y organizada sobre la base de una subyacente crítica a la realidad. El carácter no canónico de esta esta utopía provendría de la negación del no hay tal lugar, pues el hablante contextualiza lugares heterotópicos, concretos, apostados no en las ciudades, sino en campos y villorrios. Lo mismo pasa con el tiempo: el imaginario rokhiano no proyecta un porvenir, más bien poetiza 
una colección de pretéritos suspendidos. Por último, la sociedad feliz, racional y profiláctica es reemplazada por una contrasociedad de sujetos marginales, mujeres, rotos, choros, cantores populares, gañanes, pacos, compadres, curas rurales, bandidos, de duros trabajos y dramáticos avatares:

debajo del parrón, sentado en enormes piedras, recordando y añorando lo copretérito y denigrando a los parientes cacho a cacho de cabernet talquino y la sopaipilla lloviendo, con poncho, y completamente mojados, entre naranjas y violetas, acompañados del cura párroco y borrachos [...] sirvámoslo buendoso puré de papas en manga de camisa por Renca o Lampa, acompañados de señoras condescendientes y mucho vino tinto, pero más de bastante y mucho, cuando ojala se celebre el onomástico del carnicero o el santo del paco de la comuna y la niña de la casa os convida a que recitéis como un cualquier maricón del "Pen Club". (Epopeya de las 13)

Ciertamente, no es la utopía de Moro, Campanella o Bacon. No se centra en el hombre, sino en los lugares y en el derroche dionisíaco de la naturaleza. Cuando los rústicos compadres rokhianos saben, por ejemplo, que el mejor asador es el que se hace de maqui, manifiestan un conocimiento que surge entre el ser humano y el ambiente. Para de Rokha, el ser humano es una especie de catalizador de las fuerzas de la naturaleza. Esto nos remite nuevamente a los territorios del cuerpo. $\mathrm{Si}$, como decíamos, el afuera nunca está afuera de nosotros, lo que entendemos por sujeto es un "punto cero", un lugar donde "los caminos y los espacios vienen a cruzarse", pues "todo cuanto toca al cuerpo [... lo] hace alcanzar su pleno desarrollo" (Foucault 15-16). De acuerdo a Foucault, el cuerpo "en su materialidad, en su carne" (15), es el núcleo de las utopías. No es sólo que las utopías se encuentren inscritas en el cuerpo, sino que emergen de este. La historia de un cuerpo, agreguemos, es la historia de sus utopías. 


\section{Referencias}

Alaimo, Stacy. Bodily Natures: Science, Environment, and the Material Self. Bloomington e Indianapolis: Indiana University Press, 2010.

. "Material Engagements: Science Studies and the Environmental Humanities". Ecozon@ 1 (otoño 2010):69-74.

Aínsa, Fernando. "Del espacio mítico a la utopía degradada. Los signos duales de la ciudad en la narrativa latinoamericana". Revista del CESLA 1 (2000): 24-38.

Albán, Adolfo. "Comida y colonialidad: Tensiones entre el proyecto hegemónico moderno y las memorias del paladar". Calle 14 vol. 4 / 5 (2010): 10-23.

Alegría, Fernando. Literatura chilena del siglo XX (segunda edición). Santiago: Zig-Zag, 1967.

Allen, John. The Omnivorous Mind: Our Evolving Relationship with Food. Cambridge, Massachusetts, Londres: Harvard University Press, 2012.

Augé, Marc. Los no lugares. Espacios del anonimato: Una antropología de la sobremodernidad. Barcelona: Gedisa, 2000.

Bataille, George. La felicidad, el erotismo y la literatura. Ensayos 19441961. Buenos Aires: Adriana Hidalgo Editora, 2001.

Bennett, Jane. Vibrant Matter: A Political Ecology of Things. Durhamn, Londres: Harvard University Press

Concha, Jaime. "Función histórica de la vanguardia: el caso chileno". Revista de Crítica Literaria Latinoamericana 48 (1998): 11-23.

De Rokha, Pablo. Los gemidos. Santiago: Editorial Cóndor, 1922. . Epopeya de las comidas y las bebidas de Chile. Canto del Macho Anciano. Santiago: Universitaria, 1965. . Mis grandes poemas: Antología. Santiago: Nascimento, 1969. . El Amigo Piedra. Santiago: Pehuén, 1990. 
- Epopeya del Fuego: Antología. Selección, prólogo, notas y bibliografía de Naín Nómez). Santiago: Universidad de Santiago, 1995.

Fernández-Armesto, Felipe. Historia de la comida: Alimentos, cocina y civilización. Barcelona: Tusquets, 2009.

Ferrada, Ricardo. "Poesia, (des)borde e intervención de lo real en de Rokha y Neruda". Literatura y Lingüística 11 (1998): 49-74. Web[7]. 06 diciembre de 2012.

Ferrero, Mario. Pablo de Rokha: guerrillero de la poesía. Universitaria: Santiago, 1967.

Fischler, Claude. El (h)omnívoro. El gusto, la cocina y el cuerpo. Barcelona: Anagrama, 1995.

Foucault, Michel. El cuerpo utópico. Las heterotopias. Buenos Aires: Nueva Visión, 2010.

Fromm, Harold. The Nature of Being Human: From Environmentalism to Consciousness. Baltimore: John Hopkins University Press, 2009.

Frye, Northrop. "Varieties of Literary Utopias". Daedalus vol. 94/2 (primavera 1965): 323-347

Glotfelty, Cheryll y Fromm, Harold. The ecocriticism reader: Landmarks in literary ecology. Athens / Georgia: University of Georgia Press, 1996.

Gramsci, Antonio. Literatura y vida nacional. México: Juan Pablos Editor, 1998.

Lamberg, Fernando. Vida y obra de Pablo de Rokha. Santiago: Zig-Zag, 1965.

Lavín Cerda, Hernán. "La poesía de Pablo de Rokha: Chile entre la epopeya y el cataclismo". Cuadernos Americanos, año XLII, vol. CCXLVIII (1983): 82-102.

Montecino, Sonia. La olla deleitosa: cocinas mestizas de Chile. Santiago: Catalonia, 2005.

Nietzsche, Frederich. El nacimiento de la tragedia. Madrid: Alianza Editorial, 1980. 
Soler, María del Carmen. Banquetes de amor y muerte. Barcelona: Tusquets, 1981.

Rabelais, François. Gargantúa y Pantagruel. Buenos Aires: El Ateneo, 1956.

Rodríguez Monarca, Claudia. “Metatextos literarios de la vanguardia chilena (1914-1938)". Estudios Filológicos 43 (2008): 169-178.

Sepúlveda, Fidel. "Pablo de Rokha, una forma poética". Aisthesis 5 (1970): 147-171.

. "Estética: Educación de los sentidos y sentido de la Educación". En Aisthesis 29 (1996): 42-50.

Sepúlveda, Magda. "Para una entrada en la imaginación poética alimentaria chilena". Revista Chilena de Literatura 86 (abril 2014): 199-213. 